\title{
OBSERVATIONS
}

ON THE

\section{RADICAL CURE OF CLUB-FOOT,}

\section{AND EXHIBITION OF OASES WHICH HAVE BEEN OPERATED ON.}

$\mathbf{B Y}$

RICHARD DAVY, M.B., F.R.S.E., F.R.C.S., SURGRON IN OHARGE OF THE ORTHOPAFIO DEPABTMBNT, WESTMINSTER HOSPITAL.

Received August 28th, 1884-Read February 10th, 1885.

As much thought has been bestowed within the last decade on the radical cure of confirmed club-foot, it may not be devoid of interest to recapitulate some of the leading facts gained by experience, and to submit conclusions thereon to the judgment of this Society.

I will divide the consideration of the subject under the following headings :-

1. Some reasons that have suggested operative procedures in cases of intractable club-foot.

2. The cases especially suited for operation.

3. The operation itself, the description of its details, and the necessary instruments.

4. The list of operations (26) performed by myself ; and notes of other cases operated on by British and foreign surgeons. 
5. The exhibition of casts taken before and after operation, the osseous wedges removed, and living specimens of the results gained.

6. Concluding remarks.

1. Some reasons that have suggested operative procedures in cases of intractable club-foot.

The obstinate character of severe forms of club-foot, its general tendency to get worse unless subjected to continued treatment, and the discouraging relapses occurring even after proper treatment has been employed, may be mentioned as important grounds for reconsidering the usual methods of practice in vogue up till 1874. My experience showing how absolutely useless instrumentation alone was, I carefully considered the operation of removal of the cuboid bone, an operation that had been suggested by Dr. Little in 1854, and practised by Mr. Solly, of St. Thomas's Hospital, also in 1854.

From an anatomical point of view no structure of special importance is removed either in excision of the cuboid bone, or in the excision of a wedge at the transverse tarsal joint, if the operation described hereafter be practised.

2. The cases especially suited for operation.

I have never yet operated on any case that had not been previously subjected to orthopædic treatment; in some cases such treatment had been carried out during the whole of the patient's lifetime; whilst in others the condition was so incorrigible as to have necessitated the abandonment of treatment as hopeless.

3. The operation itself, the description of its details, and the necessary instruments.

The operation consists of the removal of an osseous wedge at the transverse tarsal joint; this operation has hitherto been confined to cases of talipes varus and equinus, with their combination. I will describe the operation for talipes varus first, then that for equinus.

(1) The operation for tatipes varus.-The patient being 
under the influence of an anæsthetic, and an elastic bandage being placed on the leg after elevation, an oblong piece of skin is excised from the outer side of the foot over the cuboid. This should include the distended and hypertrophic bursa and should correspond nearly with the size of the base of the osseous wedge required. On the inner side of the foot, at the stereotyped crease of skin, and in a line over the astragalo-scaphoid joint, a vertical cut is made of sufficient length to include the thickness of the scaphoid bone; these two imaginary lines, drawn across the dorsum of the tarsal arch, represent roughly the superficial area of the triangular piece of bone to be removed. Next, keeping close to the bones, elevate the tendons, nerves, arteries, and veins with the blunt curved knife on the dorsum, until the triangular space has been cleared from the outer to the inner side, for the transit of the kite-shaped director. Having passed the director between the tarsal bones and the soft structures above direct the probe-pointed saw successively along the grooves on the under surface of the director, and saw the wedge out with precision. It is usually better to saw the distal side of the wedge first, and the ankle-joint side last.

The blunt curved knife is next used on the plantar aspect of the wedge, the operator again keeping close to the bones, and lifting out the wedge in one piece by the aid of strong pointed bone forceps. The wedge usually embraces the component bones of the transverse tarsal joint, the cuboid bone invariably predominating; and portions of the bones anterior to the transverse tarsal joint, according to the condition of the deformity. Many of these osseous wedges are exhibited to the Society. One shows the component bones of the transverse tarsal joint alone, viz. astragalus, os calcis, scaphoid, and cuboid. Another shows portions of every one of the tarsal bones, and the bases of the four outer metatarsal bones also. (Case 25.)

By this method of operating, simple or compound wedges of bone may be removed with ease and precision; 
their form can also be tested, as they each appear in the shape of one neat block instead of the débris of a piecemeal and haphazard dissection.

I prefer, for many reasons, to set up these compound fractures of the foot immediately that the distortion has been corrected by rotation and abduction; the sawn surfaces of the bones should be co-adapted, and maintained in sitî on the splint, shown in the accompanying woodcut, prior to the patient's awakening from the anæsthetic.

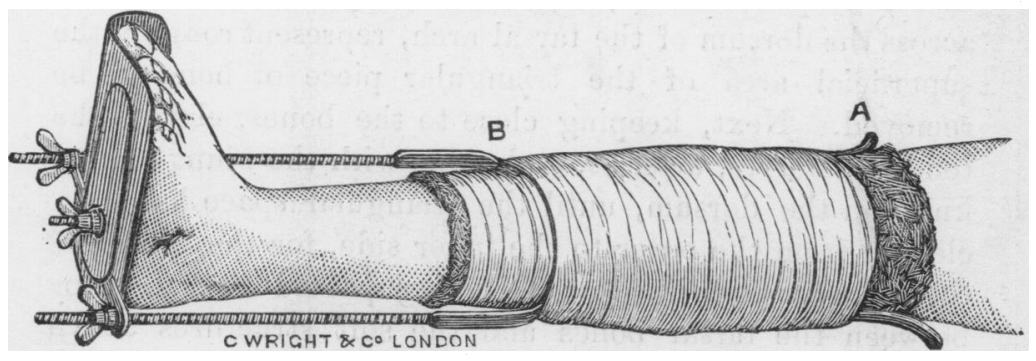

In applying the splint the patient's thigh, knee, and upper half of the leg must be first enveloped in a sock of thick fleecy wool (A) knitted to shape; over this are applied three or four layers of plaster-of-Paris bandage. To the surface of the latter the side irons are accurately adjusted, and are retained in position by additional turns of the plaster bandage (B). The footpiece slides over the ends of the side irons, and is regulated by a male screw, screw washer, and female thumbpiece on each side iron. Eversion of the anterior half of the foot is carried out by everting the moveable foot-plate on a pivot and fixing it by a thumb-screw (C). Any undue pressure can be at once removed; wide interruptions at the malleoli prevent any inconvenience from œdema; dressings (if thought to be desirable) may be readily applied, and the foot leaves the operating table a fixture.

I neither use sutures, nor dressings ; the wounds are exposed to the air. Cleanliness, however, of a strict character is maintained, and free drainage provided for. 
I have never met with hæmorrhage of a serious nature; this may be accounted for by the plan of keeping close to the bones, and bluntly dividing with the curved knife any articular or osseous branches.

(2) The operation for talipes equinus. - A few words will suffice to indicate the variation necessary in the operation for cases of talipes equinus.

Taking again the line of the transverse tarsal joint as a guide, on the outer and inner sides of the foot, immediately over this joint, two wedge-shaped pieces of skin are removed equal in extent to the amount of bone demanded. The soft structures are freed on the dorsum of the foot in the way previously described; but as the base of the osseous wedge for equinus cases is at the dorsum, and its apex at the sole the parallel wire director, instead of the kite-shaped varus one, is used. The saw is successively inserted in its grooves, and by keeping in mind the idea of a keystone, a clean wedge of bone is cut out from the dorsum to the sole of the fopt. This wedge is easily extracted in one piece, and consists of the component bones of the transverse tarsal joint, and in severe cases of portions of bone anterior to it. The splint used is the same as for varus.

4. The list of operations (26) performed by myself, and reference to those operated on by other surgeons.

The following list embraces a summary of my own cases :- 


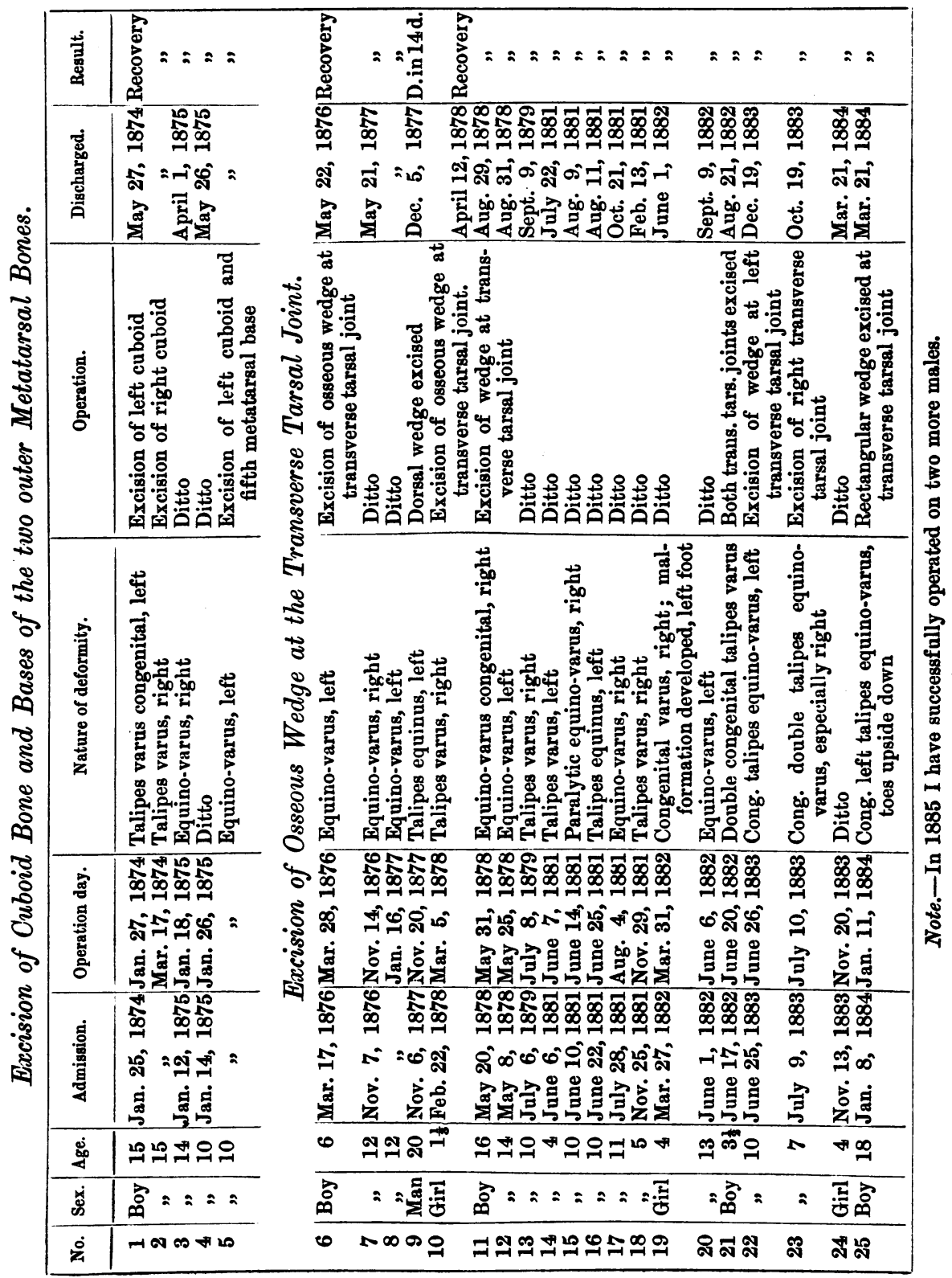


Up to the present 23 individuals have furnished 26 distinct operations. Two have submitted to the double operation at one sitting, 19 are boys, 4 are girls. Fourteen are cases of talipes equino-varus, ten are cases of varus, two cases of talipes equinus. My oldest case is 20, the youngest 1 year and 4 months. I regret to state that I have lost one out of the 26 operations, giving a mortality percentage of $3 \frac{11}{13}$.

The shortest stay in the hospital occurs in Case 10 (38 days) ; the longest stay is 175 days, in Case 22 ; this prolonged residence was due to domestic causes. The average stay in hospital, from the day of operation to the day of discharge, is 77 days.

All the patients, save the one whose case ended fatally, have been enabled to walk, and perform the daily routine of work, subsequent to the operation. In some cases, the application of a plaster-of-Paris or gum and chalk bandage has been found necessary for a time, as in the case of other resections. A high boot must be worn by others. Patients, after the operation, become absolutely plantigrade, the scar is small and well out of the line of pressure; relapses are prevented, and a useful though shortened foot results.

In recording the work done by British and foreign surgeons in similar cases, the list drawn up by Dr. Granville Faught for Dr. De Forest Willard, of the University of Pennsylvania, is the most complete. Tables are given of excisions of the cuboid bone, of the astragalus, and of wedge-shaped excisions at the transverse tarsal joint.

Amongst British surgeons the pioneer was the late $\mathrm{Mr}$. Solly, who removed the cuboid in $1854 ;^{2} \mathrm{Mr}$. DaviesColley also performed a similar operation in 1875 .

5. The exhibition of casts taken before and after operation, the osseous wedges removed, and living specimens of the results gained.

1 'Club-foot,' by Dr. De Forest Willard, Philadelphia.

2 'Medico-Chirurgical Transactions,' vol. xl (1857), p. 118.

3 Ibid., vol. lx (1877), p. 11.

VOß. LXVIII. 
On the table are thirty casts illustrating especially the condition of the feet before and after operation, specimens are also presented showing how the osseous wedge is excised in one block; in all varus cases the cuboid bone predominates.

Specimen No. 25 includes part of all the bones of the tarsus, and the bases of the outer four metatarsal bones. It is seen that the head of the astragalus is dwindled and misshapen, reminding the observer more of the concavoconvex aspect of the trapezium. The scapho-cuboid articulation is exceedingly pronounced, the bones generally are not well developed, the ligaments are tough and hypertrophied, a small bursa is to be seen over the anterior outer aspect of the os calcis.

Seven living specimens are exhibited. One a young man who was operated on seven years ago, and who has never worn any special instrument since. Two of the cases are wearing a high cork sole.

6. General observations on club-foot, with conclusions.

After an excision at the transverse tarsal joint the anklejoint (as a rule) remains unimpaired; but $I$ have seen stiffening and loss of free motion result.

Excision of an osseous wedge at the transverse tarsal joint is an operation mainly reserved for inveterate cases, and for cases where milder measures have failed.

In conclusion, for cases of talipes varus, equino-varus, or equinus, excision of an osseous wedge at the transverse tarsal joint is, in my opinion, on mechanical grounds a most valuable operation for restoring symmetry and utility to a deformed and useless foot, no case is absolutely hopeless, or to be condemned to amputation before the surgeon has given this excision fair consideration; it will, I trust, after judicial criticism, be yet further adopted, and take its place amongst the accepted joint excisions in surgery.

(For report of the discussion on this paper, see 'Proceedings of the Royal Medical and Chirurgical Society,' New Series, vol. i, p. 339.) 